\title{
Periodismo digital y Facebook durante el COVID-19 en Perú y Ecuador
}

\author{
Digital Journalism and Facebook
}

during COVID-19 in Peru and Ecuador

Recepción: 30/01/2021, revisión: 04/03/2021, aceptación: 16/03/2021, publicación: septiembre de 2021

https://revistas.uasb.edu.ec/index.php/uru

(D) Carmelo Márquez Domínguez carmelomarquez@gmail.com Investigador independiente (Ibarra, Ecuador) https://orcid.org/0000-0002-3939-9608
(ID) María Cristina Ulloa Boada ubmc@pucesd.edu.ec Pontificia Universidad Católica del Ecuador (Santo Domingo de los Tsáchilas, Ecuador) https://orcid.org/0000-0002-7747-0030

DOI https://doi.org/10.32719/26312514.2021.4.8

\section{Resumen}

El Comercio de Ecuador y El Comercio de Perú son considerados dos medios de comunicación de referencia con audiencias significativas. Aunque sus nombres se correspondan, ambos emplean discursos diferentes cuando se trata de emitir información, de acuerdo a las características de sus usuarios, que se diferencian al momento de interactuar con contenidos de diversas temáticas. La pandemia en torno al COVID-19 cambió las rutinas de cobertura y de consumo de la información. Uno y otro periódico centraron gran parte de sus publicaciones en exponer información acerca del virus y las reacciones de cada Gobierno. El objetivo de este estudio fue identificar los componentes del discurso periodístico de estos medios sobre la pandemia, a partir de los primeros casos de COVID-19 en Perú y Ecuador, así como determinar las reacciones de las audiencias a partir de las interacciones con el contenido presentado. El enfoque fue cualitativo a partir de un estudio de caso. Las técnicas aplicadas para la recolección de datos fueron la observación y el análisis de métricas. Entre los principales resultados se evidencia un discurso eminentemente informativo, aunque con ciertas dosis sensacionalistas, lo que deja entrever que, como medios de comunicación referentes, responden a prácticas periodísticas que buscan acercarse a la objetividad de los diversos asuntos, incluso en tiempos de pandemia.

\section{Abstract}

El Comercio in Ecuador and in Peru are considered two reference media with significant audiences. Both, although their names correspond, use different speeches when it comes to issuing information according to the characteristics of their users, who differ when interacting with content on various topics. The pandemic around COVID-19 changed coverage routines. Both newspapers focused a large part of their publications 
on exposing information about the virus and the reactions of each government. The objective of this study was to identify the components of the journalistic discourse with the greatest relevance, about the pandemic, exposed by both media from the first cases of COVID-19 in Peru and Ecuador, as well as to determine the reactions of the audiences accordingly. of interactions with the content presented. The approach was qualitative from a case study. The techniques applied for data collection were observation and metric analysis. Among the main results is an eminently informative discourse, although with certain sensational doses, suggesting that, as reference media, they respond to journalistic practices that seek to approach the objectivity of the various issues, even in times of pandemic.

\section{Palabras clave • Keywords}

Redes sociales, pandemia, información, Comunidad Andina, periodismo.

Social networks, pandemic, information, Andean Community, journalism.

La pandemia por el COVID-19 (enfermedad derivada del coronavirus SARS-COV-2) instaló al mundo entero y a sus sistemas políticos en el caos absoluto y en una crisis total e integral de las dinámicas sociales y, entre otras, mediáticas. Con casi la totalidad de la ciudadanía confinada, los medios de comunicación se llevaron la exclusividad discursiva de la realidad. En este sentido, se plantea la problemática sobre la eficacia de la tarea que realizó el periodismo en plena emergencia sanitaria y en un contexto de débil legitimidad que los medios de masas tradicionales ya venían arrastrando. No es de extrañar que el término infodemia, al que la Organización Mundial de la Salud (OMS) hizo referencia durante los primeros meses de la pandemia, haya aterrizado en medio de la desinformación, la incertidumbre, el miedo y los peligros para la salud de las personas.

En los casos de Ecuador y Perú, la imagen colectiva sobre la prensa empeoró, al denunciarse cierta connivencia con los Gobiernos y, por tanto, manipulación de datos reales. Esta situación no es exclusiva de dichos países. Al comenzar la pandemia, los medios de comunicación, tanto en Ecuador como en Perú, resolvieron las coberturas a partir de la réplica de la información generada por los departamentos de información de las instituciones de salud. Y ahí entraron en juego las redes sociales, que, junto a nuevos medios digitales que ocupan espacios marginales en la agenda informativa, demostraron otra vez la importancia de su uso, para bien y para mal, ante unas rutinas periodísticas poco preparadas.

Un estudio comparado de ambos medios, cuyo tratamiento de la información se definiría a partir de sus líneas editoriales, precisará la orientación de los contenidos sobre la pandemia durante sus picos más altos. A pesar de ser homónimos, no implica que sus dinámicas periodísticas sean semejantes, pues responden a intereses y características culturales diferentes. 
$\mathrm{Y}$ es precisamente en momentos de crisis cuando la democracia necesita de un periodismo de calidad que informe eficazmente a ciudades y pueblos, contrastando los datos oficiales, dudando de todo y respondiendo las preguntas para luchar contra —otra de las palabras del 2020- la incertidumbre que asoló las vidas de la sociedad internacional. Frente a la ansiedad y a las posibilidades de más pánico y caos por razones de posverdad y fake news, se anhela un periodismo interpretativo, honesto, especializado, neutral y deontológico; variables complicadas, pero no imposibles. Por lo tanto, se propone a través de este trabajo identificar los componentes del discurso periodístico más relevante sobre la pandemia, expuesto por los diarios El Comercio de Perú y El Comercio de Ecuador, a partir de los primeros casos de COVID-19.

\section{Estado del arte}

\subsection{El SARS-CoV-2 llega a la Comunidad Andina: Situación de Ecuador y Perú}

Cuando el "segundo" coronavirus - basado en un síndrome respiratorio agudo severo y bautizado por los Centros para el Control y la Prevención de Enfermedades (CDC, por sus siglas en inglés) el 7 de enero- fue identificado por primera vez en Wuhan (provincia de Hubei, China) a finales de 2019, "los primeros informes indicaban que la transmisión de persona a persona era limitada o inexistente" (Perlman 2020, 1). Muy poco tiempo después, a inicios de 2020 , se supo que no: con más de 800 casos reportados y una tasa de mortalidad del $3 \%$, la transmisión era un hecho innegable (Zhu et al. 2020). Para entonces, todavía quedaba mucho por aprender sobre este nuevo virus, su alcance de transmisión interhumana y su espectro de enfermedades clínicas. Un año después, con el trabajo de diversos centros de investigación y múltiples empresas biotecnológicas, se han dado pasos agigantados.

Los sistemas sanitarios públicos, víctimas continuas de una mala financiación en el ramo de prioridades de los presupuestos estatales, se encontraban lejos de poder soportar el duro envite que traía la coyuntura epidémica, y dependían de cuarentenas estrictas que no se cumplían - por mala educación y por razones comerciales y económicas- y de diagnósticos oportunos que llegaban tarde. Y esa era la sensación que las poblaciones compartían en redes sociales: "Estamos llegando siempre tarde en la respuesta necesaria al coronavirus". Las estadísticas (Gráfico 1) demostraron que la propagación de la enfermedad era inevitable, y esto puede visualizarse a través del incremento de casos en períodos ajustados.

La propagación mundial ya era una evidencia que esperaba ser confirmada por la OMS. Los países empezaron uno por uno a controlar rígidamente sus fronteras, suspendiendo los vuelos entrantes, principalmente desde China y, luego, desde Italia y España. En Sudamérica, Brasil fue el primero, y el de más casos de COVID-19. Sin embargo, la 
preocupación aterrizaba en Ecuador, dadas sus cifras porcentuales (Ruiz y León 2020; World-O-Meter 2021).

\section{Gráfico 1}

\section{Casos diarios de COVID-19 en Perú y Ecuador por cada millón de habitantes}

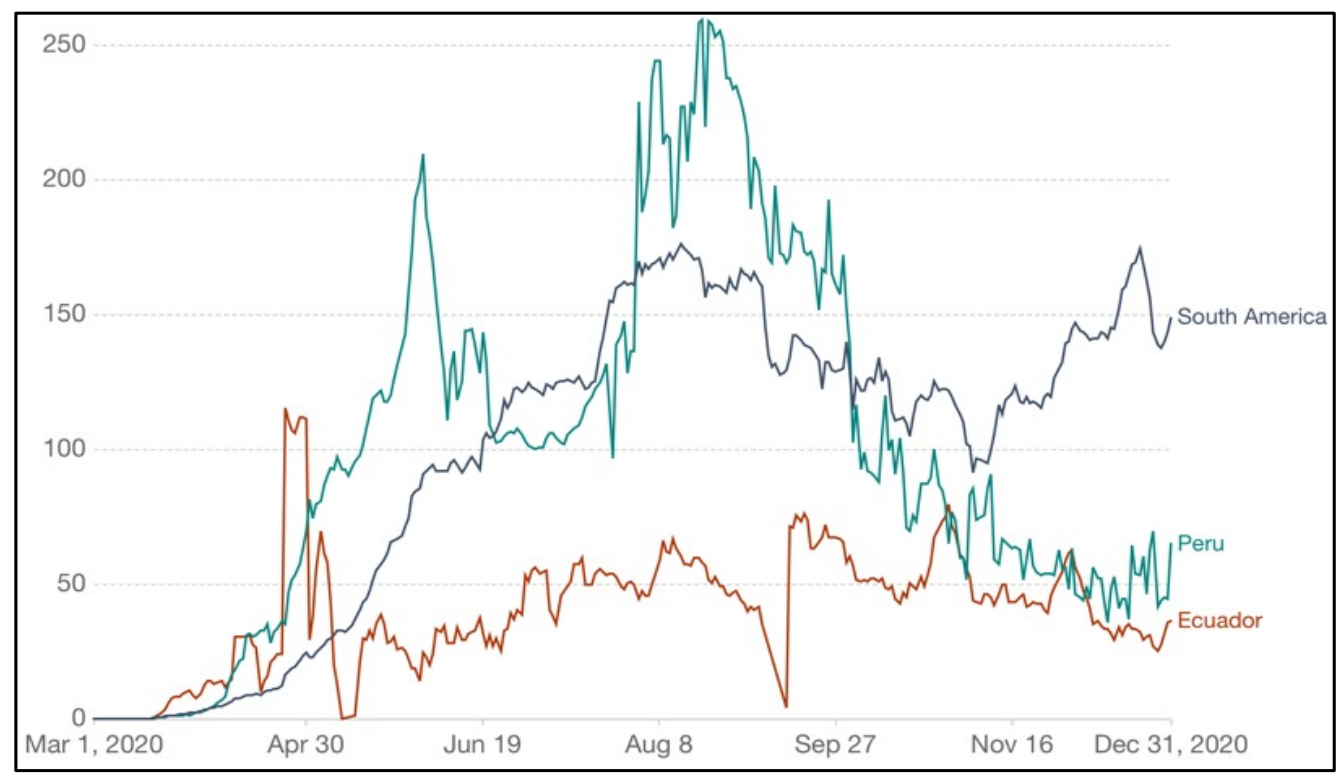

Fuente: Johns Hopkins University (2021)

Si bien el primer caso de COVID-19 data del 29 de febrero de 2020, el Ministerio de Salud Pública del Ecuador (MSP) anunció el 26 de enero la presencia de un caso sospechoso de COVID-19 que fue desestimado una semana más tarde (EC Ministerio de Salud Pública 2021). Respecto al que en verdad fue el primer caso - una ciudadana ecuatoriana residente en España que ingresó al país el 14 de febrero-, los resultados llegaron del CDC de Atlanta (EE. UU.) dos semanas después. Como en muchos países, este tiempo perdido formaría parte de la ineficaz reacción de los organismos competentes ecuatorianos durante los meses venideros.

Era necesaria una respuesta más enérgica y proactiva por parte del Comité de Operaciones de Emergencia (COE) para la contención del brote epidémico y la toma de decisiones sanitarias, una situación - y una sensación- que, a pesar de los medios de comunicación de masas, circulaba a diario a través de las redes sociales, con fotos, videos y audios. Esta deplorable gestión gubernamental llegaba al propio MSP, que no publicaba ningún reporte científico sobre los casos positivos de SARS-CoV-2 que circulaban en el país (Guerrero 2020), algo ineludible que otros países realizaban para obtener una réplica sanitaria efectiva, pues con base en los resultados los médicos de atención primaria pueden evaluar de mejor manera futuros casos sospechosos. 
Gráfico 2

Casos mensuales de COVID-19 en Ecuador, marzo-diciembre de 2020

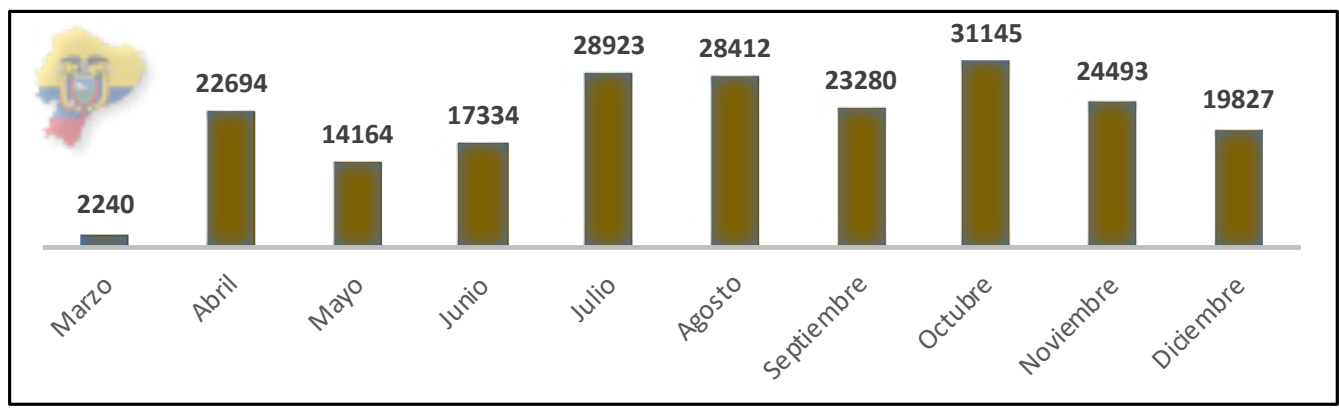

Fuente: Johns Hopkins University (2021)

Durante la primera ola en Ecuador, la agenda informativa (nacional e internacional) dejó entrar los testimonios que, a través de las redes sociales, comunicaban la grave situación de una de las ciudades más importantes del país: Guayaquil. La urbe costera mostró la dureza de la pandemia y la debilidad, en contraparte, de su sistema de salud pública (Llerena y Sánchez 2020): filas en los alrededores de los hospitales, búsqueda desesperada por Facebook de tanques de oxígeno o plaquetas de sangre, féretros de cartón, cadáveres abandonados por las calles o en las casas, cuerpos cambiados o extraviados... El caos se adueñó de la realidad social ecuatoriana. Ante esta situación, el Gobierno central declaró el estado de excepción el 16 de marzo (durante 2020, ocurriría tres veces más), cerró fronteras y estableció toques de queda. Los negocios no esenciales cerraron y la movilidad quedó muy reducida (El Comercio 2020).

Los datos oficiales (Gráficos 2 y 3), más cerca o lejos de la verdad, muestran que, hasta el momento, no se han podido reducir las cifras de casos y muertes. Y mientras las autoridades presumen una buena gestión, la opinión pública - captada a través de titulares de prensa, radio y televisión o de microtextos en redes sociales- entiende que no se respondió acertadamente a la crisis virológica: el $72 \%$ de los ecuatorianos se muestran muy preocupados por ellos y sus familias, temerosos de contagiarse de coronavirus; el $77 \%$ dice estar dispuesto a sacrificar algunos de sus derechos humanos a fin de superar esta pandemia; el $49 \%$ dice que lo peor está por venir; un $79 \%$ mostró preocupación, aburrimiento, incertidumbre y temor durante la emergencia y el confinamiento social; un $60 \%$ indicó que no ha podido trabajar ni estudiar durante el confinamiento; y el presidente Lenín Moreno tiene un 24 \% de aprobación por su gestión de la crisis del COVID-19 (Cedatos 2020). A esto habría que sumar la denuncia del 29 de abril contra el Gobierno nacional, por determinar que el coronavirus no constituye un accidente de trabajo (EC Defensoría del Pueblo 2020). 
Las cifras expuestas en el párrafo anterior representan la percepción de los ecuatorianos respecto a la pandemia, según la información que los medios de comunicación presentan como parte de sus agendas.

Al sur, en Perú, el 15 de marzo de 2020 se declaró estado de emergencia nacional mediante el Decreto Supremo N. ${ }^{\circ} 044-2020$, a fin de establecer, como todas las democracias del mundo, medidas excepcionales y temporales en la prevención de la propagación del coronavirus (PE 2020). El expresidente Martín Vizcarra generaba así los procesos jurídicos lícitos para el pertinente control de la pandemia -declarada así por la OMS el 11 de marzo - por parte de las administraciones regionales y locales, que debían priorizar el gasto del honorario público para el diagnóstico y tratamiento del coronavirus, incluida la comunicación y sensibilización de la sociedad. Lo que ocurrió después, hasta la actualidad, se resume con la incapacidad para controlar la propagación y reducir las cifras de contagios y muertes.

Y es que Perú, a un mes aproximado de la llegada del virus a América Latina, acompañaba a Brasil y Ecuador en el dolorido podio de casos y decesos (Wallace 2020). Los sucesivos y constantes informes realizados desde marzo por la Defensoría del Pueblo de Perú (que se pueden descargar total e íntegramente desde su portal web) confirman la evidencia empírica y social sobre una pésima gestión de las autoridades en general y, en particular, de determinadas regiones como La Libertad y Arequipa (PE Defensoría del Pueblo 2020a y 2020b, respectivamente). "Existen problemas económicos para comprar alimentos (suficientes solo para siete días) y medicinas [...]; los bonos son pocos para adquirir lo básico y la mayor parte de las familias no ha sido beneficiada por ningún bono" (Jaque et al. 2020, 638).

\section{Gráfico 3}

Casos mensuales de COVID-19 en Perú, marzo-diciembre de 2020

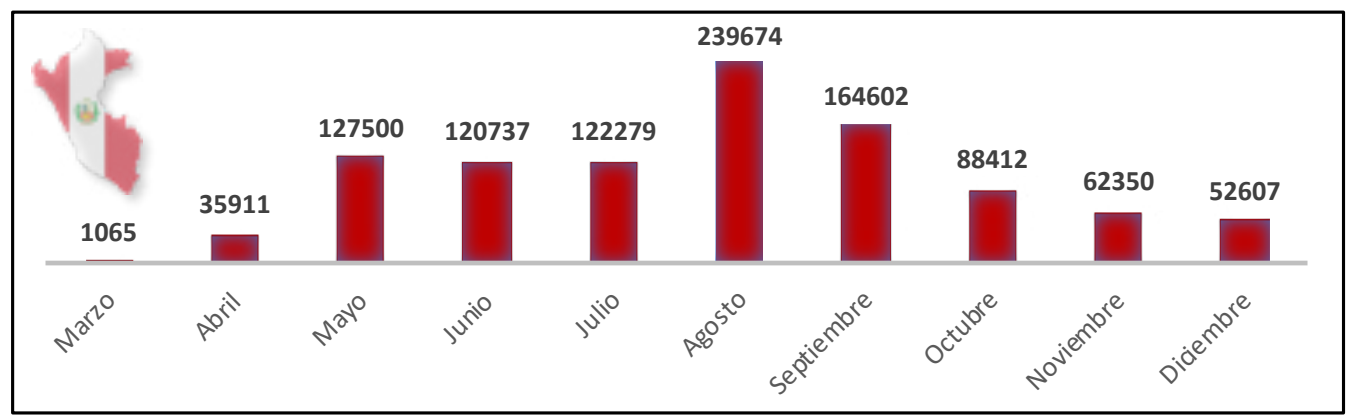

Fuente: Johns Hopkins University (2021) 
Las crisis coyunturales suelen amplificar la realidad existente, así como fragmentar las estructuras sociales que funcionaban con regularidad. La desconexión entre cargos públicos estatales y regionales o locales también (como en España, entre tantos otros países) se hizo evidente, y dio lugar a diferencias en el recuento de datos, a una lesión del derecho a la atención sanitaria indiscriminada (Amnistía Internacional 2021) y a una vulneración de derechos sociales en sectores específicos, lo que no transmitía sino una imagen impropia en cuanto a los mínimos de profesionalidad y responsabilidad que se exigen a los funcionarios encargados y representantes públicos.

Como consecuencia de la pandemia, inició una crisis que impactó duramente en el desempleo (PE Instituto Nacional de Estadística e Informática [INEI] 2020), aumentó en cinco puntos la pobreza (CEPAL 2020) y, además, obligó a la ciudadanía, como en Ecuador, a salir para buscar trabajo (Montoya 2020). En última instancia, lo que aumentó fue el empleo precario, informal y forzoso, situación que no hace sino empeorar la ya muy crítica amplificación exponencial del virus y la quiebra total del sistema sanitario: "La falta de capacidad para controlar los poderes mundiales se transforma en un principio de incertidumbre y le resta importancia a las instituciones políticas, que tienen menos posibilidades de responder a los problemas cotidianos de las gentes" (Castells, parafraseado en Navarrete 2020).

\subsection{Periodismo digital y redes sociales: una simbiosis primordial}

Durante la pandemia de un virus cuyo ácido desoxirribonucleico (información) ha sido y es investigado constantemente, se ha visto como nunca la necesidad de establecer un puente transdisciplinario entre la naturaleza y las ciencias sociales. Y aquí es donde entra protagónicamente el periodismo digital, de datos, de investigación y científico (especializado). En tanto todo es información, no hay sociedad sin ella. Todo ocurre a un clic de distancia mediante los aparatos tecnológicos. El ser humano necesita estar al tanto de lo que acontece a su alrededor. "A la luz de los hechos, ahora es posible afirmar que las diferentes formas de comunicación se dan al mismo tiempo y como nunca antes" (Márquez, Ulloa y Ramos 2018, 1066).

Desde lo cuantitativo, con el bit y la teoría matemática (Shanon 1948), hasta lo "cualitativo de la información, con el intercambio, paradigma social y estructuras de poder" (Márquez, Ulloa y Ramos 2018, 1066), todo es información: el universo es solo información cuántica; no se compone de materia o energía sino de información (Vedral 2018).

Los medios tradicionales como la prensa, la radio y la televisión han tenido que cambiar para adaptarse a esta nueva forma de comunicar. También han aparecido nuevos mecanismos para estar informado. Esta realidad empieza gradualmente a materializarse a principios de los años noventa (Salaverría 1999); mediante tendencias, convergencias y disrupciones, se llega al presente. Desde entonces, el carácter sinérgico de la tecnología 
marcaría los procesos productivos y comunicacionales de nuestra era a nivel mundial. Algunos de los periódicos se animaban a lanzar las primeras ediciones digitales en la World Wide Web, cuando tan solo era la copia de periódico tradicional subido a la red. A medida que evolucionaba la tecnología, los profesionales también lo hacían, y empezaron a generar información propia para internet. El número de periódicos digitales se multiplicó en los países avanzados.

Tras tres décadas, varias crisis financieras y comerciales y un eterno llanto en torno a que el periodismo está en peligro, la comunicación digital y los nuevos modelos de negocio informativos ya no solo son un hecho, sino que son pasado. Esta evolución de la prensa digital deja una serie de características fundamentales:

1. La interactividad: la forma en que el usuario interactúa o se comunica con el medio emisor, con distintos estadios de intensidad. Las audiencias tienen más protagonismo y oportunidades.

2. La multimedialidad: la implementación de texto, sonido, imagen y videos en una misma página web o noticia publicada. Aquí cabe señalar la capacidad "transmediática" de los medios sociales (Jenkins 2006).

3. La hipertextualidad: enlaces o hipervínculos que permiten una lectura transversal y horizontal, mucho más profunda y compleja; no necesariamente más clara ni, para nada, lineal. Es la clave de la red.

4. Actualización permanente: información instantánea e inmediata, incluso "cuántica" (Ramos et al. 2020). Ya no solo quedan lejos las relaciones europeas de sucesos cuya periodicidad era semestral o anual; tampoco hay que hablar ya de las gacetas francesas mensuales o semanales; incluso "suena a prehistoria" - o, cuanto menos, a desfasada - la periodicidad diaria. Las audiencias hoy asumen la información al segundo.

5. Personalización: como ocurre con otras esferas de la comunicación, el marketing y sus técnicas se han "adueñado" del asunto de informar. Hoy, a través de las aplicaciones y de la aceptación de muchas condiciones, los usuarios-ciudadanos pueden configurar sus preferencias de un modo muy detallado, fragmentando más todavía — si cabe - la realidad.

Y, con las redes sociales, al periodismo ( $\mathrm{y}$ a sus estructuras políticas y económicas de poder) le tocó aceptar un rol menor. La gran victoriosa es la audiencia, pero no necesariamente la democracia, el debate y la discusión sana: sin educación, tal y como se ha visto en numerosos casos sociológicos, la democracia no puede ganar. Esta sería otra tela - muy larga - que cortar.

Con estos espacios donde un grupo de personas se relacionan entre sí, se hace realidad la famosa teoría de los seis grados. Con la creación de perfiles públicos de distintas personas con diferentes propósitos, cada una compartiendo gustos $y$, sobre 
todo, diferencias, surge una nueva estructura socioeconómica y cultural, pues las redes sociales invaden todos los escenarios de la vida.

Tras - y antes de- muchos prototipos, llegó en 2004 Facebook, la gran red social. Claro que Instagram y WhatsApp (hoy propiedad de Facebook) son fundamentales y, por supuesto, Twitter tiene un éxito muy importante, pero por el momento no hay quién supere el poder de Facebook, al menos en el caso de Latinoamérica y, en ella, Ecuador y Perú. Interesante y entretenido al permitir subir y compartir imágenes, videos y transmisiones en vivo, Facebook es, además, un portador importantísimo de noticias para las débiles democracias y de primer nivel informativo para sus ciudadanías.

Las infinitas posibilidades de comunicación cambiaron para siempre la forma de consumo de las audiencias. La participación y la interacción hacen que la producción de información se maximice y se propague sin control. El diccionario de Oxford entronizó el neologismo post-truth ('posverdad') como "palabra del año" y las fake news son ya preocupación de las organizaciones internacionales por su papel brutal en las democracias y en la geopolítica regional y mundial.

En el entorno digital, donde todos pueden producir contenidos informativos, que anteriormente eran suministrados por empresas periodísticas, "la verdad ya no es tan relevante, porque importan más los seguidores o las entradas que el prestigio de la fuente o del profesional que firma" (Elías 2018, 1). Los actores políticos alientan la circulación de información falsa que busca desestabilizar o interferir en procesos democráticos y, por su parte, los medios de comunicación, por la actualización e inmediatez, descartan estándares de profesionalidad, honestidad e independencia (Aparici y Marín 2019).

Alvin Toffler (1992) menciona el término prosumer en su libro La tercera ola, publicado en 1979. Con el desarrollo de la web 2.0 nace un nuevo paradigma del consumidor, al que las marcas no solo deberán convencer, sino escuchar. La ciudadanía "prosumidora" se siente fuerte y percibe su protagonismo, pues puede producir y consumir en un simple parpadeo.

Mientras tanto, los portales web usan las redes para invitar a esta audiencia a ingresar a sus contenidos, viniendo a ser - dependiendo de la red social- como micropastillas de información que proporcionan un lead o resumen de la noticia. Un instrumento más al servicio del periodismo para conectar mucho más fácilmente con sus lectores, en una especie de convivencia virtual.

\subsection{Distintos modelos mediáticos homónimos, vecinos y de referencia}

Como antecedente histórico del periodismo en Latinoamérica, es vital mencionar que su profesionalización inició en Argentina. Era la década de 1930 y la formación era predominantemente europea. En la actualidad, casi un siglo después, hay más de 1700 escuelas y facultades de comunicación y periodismo. En Ecuador, hay que mirar 
a la década de 1940 para hallar la primera oferta universitaria en periodismo (Márquez, Moreno y Ruiz 2019).

Previamente, ya existía el diario El Comercio. Desde su fundación, en 1906 y en un ambiente de agitación política por la descomposición del Partido Liberal, esta cabecera ha mantenido su línea editorial desde el sentido de independencia - si bien esto ha quedado en entredicho con la coyuntura gubernamental de Lenín Moreno- y la defensa de las libertades individuales y colectivas (Márquez, Moreno y Ruiz 2019). Coincidiendo con su centenario, el rotativo ecuatoriano desarrolló un código deontológico al que, en 2012, seguiría un manual de buenas prácticas para redes sociales (Grupo El Comercio 2006 y 2012).

En definitiva, El Comercio es un periódico de referencia en Ecuador, y ostenta un reconocimiento y una trascendencia nacionales sin parangón. Hoy, no solo cuenta con su edición impresa, sino que su página web se encuentra entre los enlaces más visitados en Ecuador. Asimismo, ha resignificado su posicionamiento a través de una lógica empresarial en torno a las redes sociales, lejos de toda obsolescencia y muy cerca de la vanguardia tecnológica en la región.

De este modo, cuenta con un modelo de medio impreso moderno y notablemente adaptado a las exigencias actuales del mercado y de las nuevas y múltiples audiencias. Posiblemente por ello, tiene una redacción integrada multimedia de su equipo web y de su contraparte impresa, un proceso que facilita la actualización decidida de temas y un espacio de información en tiempo real. No es casualidad que este proceso coincidiera con los años 2006 y 2012, ya indicados.

En el escenario de las redes sociales, El Comercio sigue siendo la referencia en Ecuador, con su innovación informativa y narrativas digitales, cuyo fin no es otro que el de mantener informada a la sociedad, pero apuntando a audiencias de grupos más jóvenes. El Comercio, mirando otros paradigmas mundiales, ha entendido a la perfección la creación de contenidos con discursos precisos y breves, imágenes, videos, transmediación, fotografías en $360^{\circ}$ y diferentes herramientas, como las trasmisiones en vivo que hace en Facebook.

Ahora viajamos de Quito a Lima para mencionar a uno de los medios más añosos de Perú: El Comercio, cuyos inicios se remontan a 1839, también en un ambiente político tenso.

La aparición del diario El Comercio marca indudablemente un hito en la historia del periodismo peruano y coincide con el comienzo de una nueva etapa en la historia del país: en lo político, búsqueda de estabilidad; en lo económico, la llegada y promoción de los capitales y las prácticas comerciales que harán posible la iniciación del Perú en el capitalismo. (Gargurevich 1991, 66) 
Gráfico 4

Presencia en Facebook de El Comercio de Perú y El Comercio de Ecuador
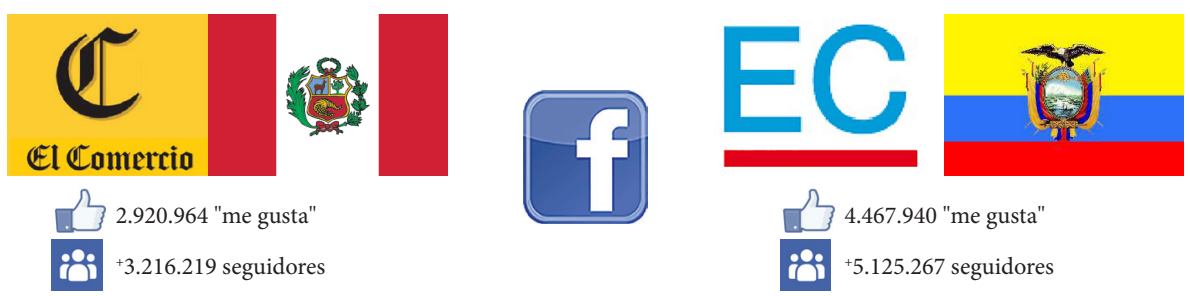

Fuente y elaboración propias

Como en siglos anteriores en España, Francia y Reino Unido, la burguesía emergente deseaba controlar el periodismo a fin de ostentar el cuarto poder. "Sus conexiones con el poder aristocrático de entonces le permitieron tener un crecimiento sostenido a través de todas las crisis que sufrió el país" (Ramos Obregón 2019, 65). Tras una expropiación durante el Gobierno militar de 1968-1975, el medio mantuvo una posición hegemónica en la opinión pública, situándose como un referente.

Ya en el siglo XX, el diario peruano se decidió a crear ediciones locales y regionales dentro del país, aunque su principal audiencia se hallaba en la capital. Su presencia en Perú era absoluta, por lo que en 2013 necesitó de unos recursos humanos competentes "para ejercer tanto en la parte del diario impreso como en la versión web, a partir de la llamada integración o convergencia de redacciones" (Cruz Valdivia 2018, 11), tal y como hizo su homónimo ecuatoriano.

El Comercio apunta, desde entonces, a la innovación en tanto la nueva lógica del modelo de negocio lo permite y lo exige. En los últimos tiempos, el "Decano de la Prensa Peruana”, un gran medio periodístico y una de las empresas periodísticas más importantes, ha crecido mucho en su edición digital, para lograr una efectiva cobertura de política, actualidad y los temas más importantes en el país y el mundo, como el COVID-19.

La página del diario El Comercio de Perú en Facebook fue creada el 28 de abril de 2009. Además de la principal (verificada), cuenta con otras doce páginas especializadas en esta red social.

Todo lo que se encuentra en la versión impresa también se visualiza en la versión digital. En algunas ocasiones, la información es más extensa en la plataforma web que en la impresa, y no necesariamente se imprime todo lo que se publica en el sitio web.

De acuerdo con información que consta en su portal web, "los contenidos periodísticos que se editan tanto en formato impreso como en las distintas plataformas digitales, por más profundos y complejos que sean, deberán ser en lo posible interesantes, entrete- 
nidos y con una redacción al alcance del lector". También se manifiesta que la innovación y mejora responde a la búsqueda de conocimiento de su contexto y de sus audiencias.

El propósito de este medio de comunicación se relaciona con llegar a todos los niveles socioeconómicos, en ejercer desde la vocación de servicio al usuario, a su comunidad y al país.

\section{Metodología}

En dicho contexto, esta investigación quiere analizar el discurso periodístico en redes sociales de los diarios El Comercio de Ecuador y El Comercio de Perú (sujetos de la investigación), en relación con los contenidos sobre el COVID-19 y la interactividad de sus audiencias (objetivo general). Para ello, se presentará un estado del arte o de la cuestión que deriva de una revisión teórica actualizada sobre periodismo digital, redes sociales y audiencias en tiempos de coronavirus en la Comunidad Andina. Luego, se describirán los resultados obtenidos tras aplicar el recorrido metodológico diseñado, que se detalla a continuación:

Se partió de la siguiente pregunta: ¿ los medios de comunicación han experimentado desde el desconocimiento la cobertura de información durante la pandemia? Con ello, se prevé en sus discursos cierta incitación a la desinformación sobre la crisis de salud actual. Además, las audiencias, con su participación e interacción, se funden en la construcción del mensaje realizado por los medios.

Por tanto, se marcaron los objetivos de, por un lado, identificar los componentes del discurso periodístico sobre la pandemia expuesto en la red social por ambos diarios desde el primer caso de COVID-19 en Perú y en Ecuador; y, por otro, determinar las reacciones cuantitativas de las audiencias como consecuencia de las interacciones con el contenido presentado.

Con el fin de resolver la problemática y alcanzar los objetivos marcados, se decidió un método de estudio de caso. Los estudios de caso se aplican a un objeto singular en sí y por sí mismo; en esta investigación corresponde a los medios de comunicación seleccionados, con el objetivo de alcanzar una mejor comprensión del problema, direccionado al abordaje de la información en tiempos de pandemia.

Se trazó una metodología cualitativa, con técnicas de observación y análisis de métricas. La primera técnica se ejecutó de acuerdo con categorías específicas (Tabla 1), mientras que el análisis de métricas se efectuó en el marco del modelo de reducción de datos cualitativos de Mejía, cuyo proceso comprende: edición, categorización y codificación, registro y tabulación (Katamaya 2014).

Los instrumentos se construyeron desde los objetivos, para dar lugar a una ficha de observación de la realidad periodística que, con la ayuda de la aplicación Fanpage Karma, se añadió a los datos cuantitativos. 
Tabla 1

Ficha de observación individual y respectiva de cada publicación

\begin{tabular}{|c|c|c|c|}
\hline Medio & El Comercio (EC) & Medio & El Comercio (PE) \\
\hline Fecha del post & 23 feb.-21 mar. & Fecha del post & 25 abr.-30 may. \\
\hline \multicolumn{4}{|c|}{ Texto de la publicación } \\
\hline Tema & $\begin{array}{c}\text { Adjetivos } \\
\text { calificativos }\end{array}$ & INTERACTIVIDAD (CUANTITATIVA) \\
\hline Sujeto & Ciberanzuelo & Compartidos & Comentarios \\
\hline Encuadre & Emoticones & Me gusta & Me asombra \\
\hline $\begin{array}{c}\text { Abordaje } \\
\text { del tema }\end{array}$ & $\begin{array}{c}\text { Función } \\
\text { del discurso }\end{array}$ & Me entristece & Me divierte \\
\hline $\begin{array}{c}\text { Formato } \\
\text { audiovisual }\end{array}$ & Sensacionalismo & Me enoja & Me importa \\
\hline
\end{tabular}

Fuente y elaboración propias

Entre las variables cualitativas de la ficha aplicadas a cada publicación seleccionada en la muestra, se encontraban las siguientes opciones:

- Temas, sujetos y adjetivos calificativos: sin especulaciones previas, o dependía de la realidad informativa encontrada.

- Encuadre: neutro, negativo o positivo.

- Abordaje del tema: primario o secundario.

- Función del discurso: referencial, expresiva, apelativa, metalingüística, poética o fática.

- Formato audiovisual: texto (nada), audio, imagen, video o directo.

- Ciberanzuelo (clickbait), emoticonos y sensacionalismo: en estas tres variables, a partir de su presencia o ausencia, las opciones eran sí y no.

Entre las redes sociales que usan los medios, se eligió finalmente Facebook por ser la más usada, sin duda alguna, en la región geopolítica analizada, según Hootsuite (2019). Y, entre tantas cabeceras digitales periodísticas, se eligió El Comercio de Ecuador y de Perú porque representan, con pocas dudas también, el periodismo de referencia en ambos Estados de la Comunidad Andina. 
La delimitación temporal, no obstante, no puede ser ecuánime para uno y otro caso por razones de contextos y tiempos distintos en torno a la evolución del virus. De este modo, para El Comercio de Ecuador se decidió analizar todas las publicaciones de Facebook que van del 23 de febrero (una semana antes del primer caso de coronavirus en el país) al 21 de marzo de 2020 (jornada en la que dimite la ministra de Salud). Para El Comercio de Perú, el intervalo temporal se compuso del 6 de marzo (primer caso de coronavirus) al 30 de mayo de 2020 (día representativo del pico de mayor contagio desde que inició la pandemia).

Dispuesto el universo de estudio, se elaboró una muestra verdaderamente representativa a través de tres filtros o normas secuenciales aplicados a las métricas e información que se consiguió desde Fanpage Karma:

1. Por la aplicación de palabras clave: grupo léxico (COVID-19, COVID, pandemia, crisis sanitaria, epidemia, SARS-CoV) con relación a la temática coronavirus.

2. Eligiendo una publicación representativa por cada día.

3. En caso de que hubiera más de una (lo esperado), se tomó la publicación "elegida" por la audiencia, en tanto ostentaba la mayor interactividad en función del número de comentarios y compartidos.

\section{Análisis y resultados}

\subsection{Abordaje periodístico de la pandemia en El Comercio de Perú}

Del medio de comunicación El Comercio de Perú, en la delimitación temporal señalada, se determinó, rápidamente y en primera instancia, una notable ausencia — salvo excepciones- del uso de formatos multimedia. Esto lleva a una relativa sorpresa en tanto lo habitual en el uso de las redes sociales hoy - y más en Facebook, por su heterogeneidad y abundancia de formatos- es utilizar todas las posibilidades narrativas que el medio permite, a fin de captar a una audiencia acostumbrada a una lectura "transmediática". Así, para este periódico digital, Facebook solo es un espacio de acceso directo y enganche hacia su propio portal web, es decir, no existe un trabajo de construcción de contenidos. Por el contrario, se dedica casi exclusivamente a colocar enlaces que vinculan la información, acompañados de un texto que se extrae literalmente del título, entradilla y/o cuerpo del texto.

Por otro lado, resulta notorio que parte de la información que publica en la red social corresponde a notas de agencia, cuya fuente no se expone en el muro. Al teclear el contenido en cualquier buscador, se puede visualizar que el texto es idéntico - errores ortográficos y gramaticales incluidos- al de otros medios de comunicación. Desde aquí, 
cabe considerar el resultado como un factor para comprender cómo se abordó la cobertura del medio en tiempos de pandemia. Y es que, ante el predominio de una información de agencia (copiada y pegada), puede entenderse que las formas de llevar la cobertura no correspondieron al despliegue de los periodistas "en el campo de acción". La mayoría de las noticias presentadas hacen alusión a una sola fuente, cuya referencia se da en el contexto de una rueda de prensa o boletín. Esto responde a las limitaciones que tuvieron los profesionales de la información para desplegarse bajo las condiciones que se impusieron en el país para la cobertura, ante el desconocimiento de las medidas de bioseguridad.

Respecto al contenido de las publicaciones en Facebook de El Comercio de Perú, se demuestra, con un 18,42\%, una presencia importante de información de "farándula" o "show business", que involucra a personajes públicos del mundo del cine, de la música, de la televisión, etc., y su contagio por COVID-19. Asimismo, se aprecia un proceso de estigmatización sobre la enfermedad derivada del coronavirus, con un $25 \%$ de casos particularmente aporofóbicos, con referencia a la población inmigrante de origen venezolano que, luego - ya fuera de la delimitación temporal de análisis de la presente investigación-, fue convocada a trabajar en áreas de la salud, desplazando sus labores como comerciantes.

La información, en general, cumple funciones referenciales y, en un mínimo de casos, apelativa, al dejar preguntas al lector para que participe opinando, en la misma tribuna social de Facebook, sobre los datos, que suelen estar enmarcados en declaraciones del Gobierno. La representación de los hechos, de acuerdo con el estilo del diario, se enmarca desde el hábito de un lenguaje fresco y cercano a las audiencias, con una usanza de adjetivos en relación con la función poética y expresiva del texto. Así, pues, mientras el 47,22\% de las publicaciones fueron informativas, el 27,77 \% pueden ser caracterizadas como sensacionalistas.

Los formatos que usa este medio de comunicación en su mayoría (75 \%) corresponden a texto transcrito desde su propio portal web, mediante enlaces que llevan a los usuarios a la información completa. Solo el 27,77 \% son imágenes originales, publicadas en relación con las temáticas a exponer. Entre los resultados, se hace necesario resaltar un paradigma en torno al abordaje periodístico del tema (COVID-19, coronavirus, SARS-CoV-2). Por ejemplo, el 25 de abril de 2020, cuando en Perú se hablaba de los primeros casos de coronavirus, una de las publicaciones más comentadas correspondió a la noticia sobre un periodista famoso del país que anunció su forma de "matar al coronavirus". El titular afirma que el protagonista "mira el rostro a la muerte todos los días" (sic). El contenido era una entrevista en la que no puede contener sus lágrimas. Cuando se accede a la nota completa en la web, se puede ver un perfil del periodista, mientras que la esencia del post (el coronavirus y sus consecuencias) se desplaza al final.

La mayor parte de las noticias referentes al COVID-19 tiene que ver con las declaraciones oficiales del Gobierno de Perú; las extraordinarias, donde se aborda la temática 
de la pandemia, hacen alusión a la situación en otros países y la exposición a la enfermedad en ciudades peruanas. También sobresale la información sobre personajes públicos que se han contagiado o que buscan llegar desde otros países al Perú.

Las reacciones de los usuarios evidencian el interés por los discursos presentados. Las tres publicaciones que más interacciones generaron fueron las siguientes:

- Con 7384 compartidos, 5625 "me enoja", 4596 "me gusta” y 2185 "me asombra", una publicación del $1 .^{\circ}$ de mayo de 2020 en la que se habla sobre el acceso a "documentos secretos de agencias de inteligencia de Estados Unidos donde se menciona un colapso en el sistema de salud en Wuhan desde el mes de noviembre".

- La segunda publicación (4 de mayo) con más compartidos corresponde a una noticia de la Agence France-Presse (AFP) sobre un posible "anticuerpo monoclonal humano que impide que el virus pueda infectar células cultivadas". Fue compartida 7171 veces y obtuvo 21581 "me gusta" y 1105 comentarios.

- El 15 de mayo se publica un informe que "revela la realidad de nuestros héroes", en referencia al cuerpo de salud que, en primera línea, lucha contra la enfermedad. Esto fue compartido 6595 veces y tuvo, como reacciones principales, 9863 "me entristece", 3933 "me gusta" y 1217 comentarios.

\section{Gráfico 5}

\section{Principales resultados de $\mathrm{El}$ Comercio de Perú}

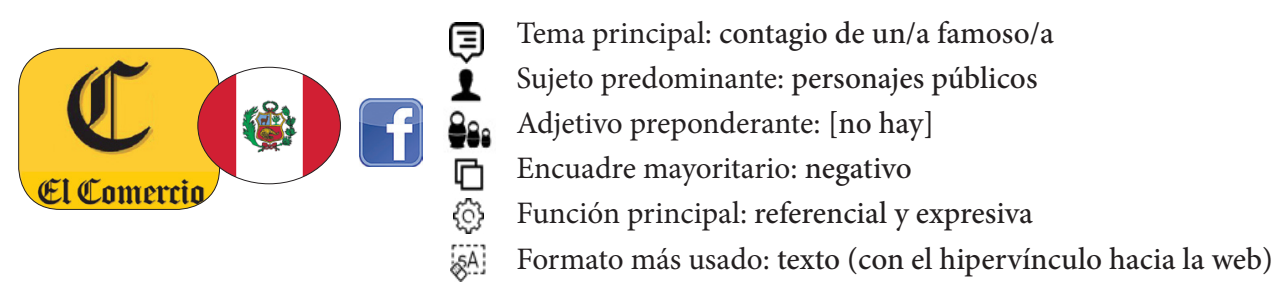

Fuente y elaboración propias

\subsection{La pandemia desde el contexto periodístico de El Comercio de Ecuador}

En cuanto a la información publicada en Facebook por El Comercio de Ecuador, se detectó que una ingente mayoría de publicaciones contenían información correspondiente a anuncios del Gobierno sobre la pandemia, acciones de prevención y decisiones, así como cifras que representan el desarrollo de la enfermedad en el territorio. En este senti- 
do, las funciones del discurso predominantes fueron la referencial, seguida de la expresiva y, en mínimos casos, la apelativa. Por lo tanto, se considera que, en el período analizado, la práctica periodística se acercó a las recomendaciones de la Organización Panamericana de la Salud (OPS) respecto a evitar el lenguaje sensacionalista y divulgar enlaces o fuentes confiables donde la población pueda encontrar información.

Por su parte, se observó una estructura del contenido basada en una narrativa digital que formula textos, imágenes, videos y transmisiones en directo, propios de la plataforma. Cuando se enlaza la información hacia el portal web, esta da continuidad y profundidad al contenido. No hay ciberanzuelos y la información se aborda de forma primaria.

Hay una búsqueda y un encuentro con la objetividad desde el encuadre de los hechos, aunque estos no se compongan de una contrastación profunda, producto de la exposición de diversas fuentes. El 88 \% son textos netamente informativos, lo que deja entrever que el medio de comunicación ecuatoriano responde a las prácticas periodísticas que buscan acercarse a la objetividad, aún más en tiempos de pandemia. Ciertamente, se informa mediante datos necesarios para la población en el contexto sanitario.

Como se puede deducir, la realidad discursiva de la página de Facebook de este medio es distinta — casi contraria- a la de El Comercio de Perú. Los protagonistas de los datos son funcionarios públicos, por lo que se considera que las publicaciones no han sido producto de coberturas de campo sino de ruedas de prensa, comunicados o boletines de las instituciones del Gobierno de Ecuador. Las noticias más compartidas corresponden a las que anuncian los nuevos contagios, las cifras en el desarrollo de la pandemia y las medidas resolutivas que fueron dándose en el transcurso de los hechos. La dinámica de trabajo de este medio de comunicación da una respuesta colectiva a la necesidad de datos concretos que los ciudadanos requieren.

Se detectaron únicamente tres publicaciones (12\%) que estigmatizaron a sus protagonistas, entre ellos las personas con los primeros casos, además de los personajes que ingresaron al país en vuelos humanitarios desde países donde la cuarentena ya se había implementado. Sin embargo, no se identifican nombres. Solo se hace alusión a los casos con palabras como "estudiantes", "mujer" y "alcaldesa".

Los encuadres noticiosos, en su mayoría, son neutros y predomina la función referencial. La imagen prevalece como formato de publicaciones (80 \%), seguida por el "directo" o "en vivo", con un $12 \%$.

Las interacciones de la comunidad de usuarios demostraron interés en estos discursos:

- El 13 de marzo, días después de haberse oficializado los primeros diez casos en Ecuador, se publica algo referente al "medio ambiente de Italia y China". La noticia fue compartida 162014 veces, generó 5288 comentarios, 21190 "me encanta" y 4162 "me gusta". De acuerdo con esta información, se puede determinar que a las audiencias las conmueven los temas relacionados con el medio ambiente y los efectos positivos y negativos que sobre este recaen. 
- La segunda noticia más comentada versaba sobre "el primer caso de coronavirus en Ecuador", una publicación del 29 de febrero que tuvo 55892 compartidos. Las reacciones más altas se relacionan con el número de "me entristece" (12 256), "me asombra" (6193), "me enoja" (6193) y "me gusta" (7424). Es evidente que la población del Ecuador esperaba esta información, pues en otros países ya se habían arrojado cifras respecto a los primeros contagios. Los usuarios permanecían expectantes y el día en que se oficializó la información las reacciones fueron inmediatas.

- Finalmente, la tercera publicación más compartida fue una del 14 de marzo sobre "la restricción de vuelos internacionales, ingresos por vía terrestre y marítima". Esta noticia obtuvo 30452 "me gusta", 8809 comentarios y 6695 "me encanta”, entre las cifras de interacción más altas. Las medidas que el Gobierno decidió como parte del plan para solventar la crisis sanitaria fueron anunciadas desde el medio de comunicación, a manera de réplica, usando el formato "en vivo", con la finalidad de dar voz a las autoridades de salud y del COE para generar la objetividad correspondiente.

\section{Gráfico 6}

\section{Principales resultados de El Comercio de Perú}

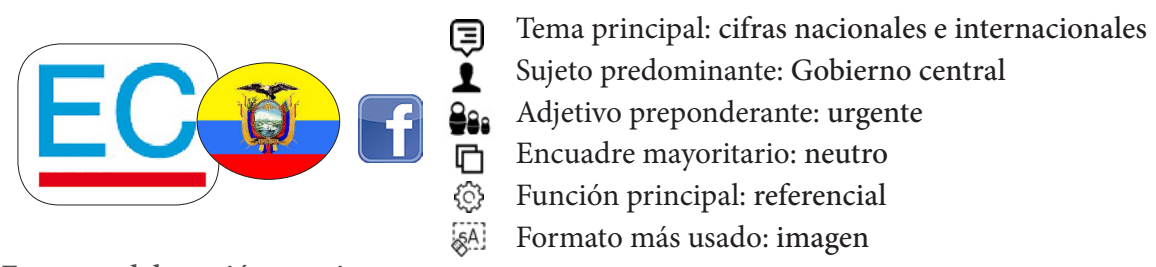

Fuente y elaboración propias

\section{Discusión y conclusiones}

Efectivamente, el diario El Comercio de Ecuador y su homónimo periodístico peruano no comparten ideología ni estilo. El modo en que abordaron la pandemia y su formato discursivo fueron distintos. Además, las audiencias de ambos medios tienen características diferentes. Este factor cultural incide indudablemente en la elección del formato y el contenido que presentan.

El Comercio de Ecuador se limita a encuadrar los temas alrededor de la pandemia en la exposición de los hechos y desde las fuentes oficiales. Esta cuestión no se corresponde con el discurso del diario peruano, que tiende a exhibir información desde el lenguaje sensacionalista, desplegando como principales publicaciones el contenido de farándula y de agencias de noticias, interactuando con la audiencia desde el desarrollo de cuestionamientos que invitan a las personas a calificar el accionar de las autoridades de gobierno y a los protagonistas de la información. 
El diario ecuatoriano usa narrativas que se adaptan al entorno del medio social, mientras que el medio de comunicación peruano, en su mayoría, comparte enlaces que llevan a los usuarios al portal web. Incluso la información que presenta como contenido en el muro en Facebook es extraída de los leads y, en algunos casos, del cuerpo de las noticias.

Según el análisis realizado, el diario de Perú despliega la información sobre la pandemia a un plano secundario; es decir, no realiza un abordaje de forma directa, con cifras, implicaciones, recomendaciones médicas, alusión al autocuidado, etc., sino que se concentra en informar lo que a sus protagonistas - en su mayoría personajes públicos- les sucede en dicho contexto. Esto implicaría una estigmatización, factor que contradice a las recomendaciones de la OPS, entre las cuales consta evitar enfocarse en el paciente cero o primer caso, evitar centrarse en el comportamiento de las personas y en su responsabilidad en la propagación de la enfermedad.

El diario El Comercio de Ecuador anuncia al paciente cero y luego hace alusión a los primeros cinco casos, pero no expone nombres ni desarrolla el discurso desde la función apelativa, solicitando la opinión de su audiencia respecto al hecho. Esto es, se limita a exponer cifras, a referirlas. Por su parte, el medio de comunicación de Perú hace alusión a casos particulares, a personas que se han contagiado, específicamente personajes públicos.

Por su meridiana refulgencia, uno y otro diario, a pesar de su cercanía geopolítica, presentan magnas diferencias al momento de transmitir información sobre la pandemia. Sus discursos y objetivos, sus abordajes de los temas y los encuadres noticiosos se encuentran alejados. Las audiencias, con su participación e interacción, se funden en la construcción del mensaje mediático.

La interacción de las audiencias representa el interés por contenidos cuyas temáticas son abordadas de manera diferente en ambos diarios. La información sobre la pandemia en relación con contagios en personajes de la farándula tuvo una mayor acogida en El Comercio de Perú, mientras que, en el caso de Ecuador, la información acerca del virus se manejó desde las fuentes de Gobierno, aludiendo a los contagios en relación a los primeros casos que se anunciaban de manera oficial.

Es notorio también que el medio de comunicación peruano no usa un lenguaje adaptado a las narrativas digitales, mientras que el diario ecuatoriano hace uso de la imagen en la mayoría de casos, aprovechando los audiovisuales para las transmisiones en vivo y cumpliendo con el cometido de la OPS, cuyo manual sobre manejo de las pandemias por parte de los medios de comunicación hace énfasis en la transmisión de información con la mayor objetividad posible, haciendo de las fuentes oficiales el recurso elemental del dato a exponer.

El diario peruano aborda la situación de la pandemia desde los ciudadanos extranjeros, representados a través de historias de vida y generando, de este modo, interacción por parte de los usuarios con el contenido. Desde ese discurso, hace que las audiencias 
estigmaticen los casos de COVID-19, en relación con el impacto que tuvo el virus en los primeros meses. Este abordaje impide la percepción de la pandemia como un elemento importante para el cuidado y la resolución de las medidas de bioseguridad, deja en un segundo plano el conocimiento acerca de la enfermedad y coloca en portada información que disipa el tema central. Las publicaciones del diario peruano, en general, no trascienden respecto a los números de casos y muertes ni contribuyen a explicar el contexto o brindar consejos de salud a la población.

El diario ecuatoriano, a pesar de que expone la información desde los medios oficiales - haciendo alusión a cifras y transmitiendo las ruedas de prensa y boletines de los organismos correspondientes-, en las notas subsiguientes se enfoca en el paciente cero o primer caso, centrándose en su comportamiento y responsabilidad en la propagación de la enfermedad. Al hacerlo, refuerza la estigmatización, cuestión que la OPS observa en correspondencia a la responsabilidad de los medios de comunicación sobre pandemias.

De igual manera, ambos diarios hacen alusión a la enfermedad como si esta pudiera ser mortal y, en el contexto de una enfermedad nueva, esa descripción puede generar pánico y paralizar a algunas personas (de acuerdo a la OPS). Sin embargo, como parte de sus discursos, también se halla una lógica optimista, reflejada en cómo la población de ambos países sobrelleva la situación. Ambas cabeceras informativas, al referirse a la pandemia, en mayor y menor grado, usan adjetivos calificativos y referencias sensacionalistas que perturban a las audiencias; en algunos casos generan estigmatización y, en otros, sensacionalismo.

Finalmente, de cara a todos los medios de comunicación del mundo pero particularmente a los dos periódicos analizados, cabe apuntar el llamado que la OPS hace a los medios de comunicación sobre el cuidado en el uso de las palabras para la construcción del discurso, al considerar que podrían tener connotaciones negativas, alimentar actitudes estigmatizantes e influir en las percepciones con respecto a las personas y a la situación en un contexto de crisis social.

\section{Referencias}

Amnistía Internacional. 2021. “Coronavirus: No solo está en juego el derecho a la salud”. Amnistía Internacional Perú. Accedido 24 de mayo. https://bit.ly/38RUZnS.

Aparici, R., y D. Marín. 2019. La posverdad: Una cartografía de los medios, las redes y la política. Barcelona: Gedisa. https://bit.ly/3u7P0De.

Cedatos. 2020. "COVID-19 cambió la vida y expectativas de los ecuatorianos. Apreciaciones de la población al 16 de abril de 2020”. Cedatos. https://bit.ly/38MJldV.

CEPAL. 2020. Panorama social de América Latina 2020. Santiago de Chile: CEPAL. 
Cruz Valdivia, C. 2018. "Periodismo digital: Experiencia en el site Dakar 2013 y la convergencia de redacciones en el diario El Comercio". Tesis para optar el título profesional de licenciado en Periodismo, Universidad Nacional Mayor de San Marcos, Perú. https://bit.ly/3pG745m.

EC Defensoría del Pueblo. 2020. "La Defensoría del Pueblo exhorta y exige al Gobierno Nacional dejar sin efecto las resoluciones que determinan que el coronavirus no constituye un accidente de trabajo". Defensoría del Pueblo Ecuador. 29 de abril. https://bit.ly/3fY5WH1.

EC Ministerio de Salud Pública. 2021. “Comunicados oficiales del Ministerio de Salud Pública del Ecuador”. Ministerio de Salud Pública. Accedido 24 de mayo. https://bit.ly/2Ka7Rw2.

El Comercio. 2020. "Presidente declara emergencia sanitaria en Ecuador por el coronavirus covid-19". El Comercio. 17 de marzo. https://bit.ly/3xOcwH5.

Elías, C. 2018. "Fake news, poder y periodismo en la era de la posverdad y hechos alternativos". Ámbitos. Revista Internacional de Comunicación 40: 1-6. https://bit.ly/3fw6RQm.

Gargurevich, J. 1991. Historia de la prensa peruana, 1594-1990. Lima: La Voz Ediciones.

Grupo El Comercio. 2006. "Manual de estilo”. Grupo El Comercio. https://bit.ly/3hRrlEm.

—. 2012. "Manual de buenas prácticas". Grupo El Comercio. 7 de mayo. https://bit.ly/3uhGt0i.

Guerrero, S. 2020. “Coronavirus en Ecuador: Una opinión desde la academia”. La Granja. Revista de Ciencias de la Vida 32 (2): 127-33. https://doi.org/10.17163/lgr.n32.2020.10.

Hootsuite. 2019. “The global state of digital in 2019”. Hootsuite. https://bit.ly/3wx7XR2.

Jaque, C., M. Tarrillo, J. Ramos, G. Pasapera, y L. Vásquez. 2020. “Aspectos económicos y de salud en tiempos de cuarentena por COVID 19 en población peruana, año 2020”. Revista de la Facultad de Medicina Humana 20 (4): 630-9. https://bit.ly/2MuwDrA

Jenkins, H. 2006. Fans, Bloggers, and Gamers: Exploring Participatory Culture. Nueva York: NYU Press.

Johns Hopkins University. 2021. “Coronavirus Resource Center”. Johns Hopkins University. Accedido 24 de mayo. https://bit.ly/3iUvoy7.

Katamaya, R. 2014. Introducción a la investigación cualitativa. Lima: Universidad Inca Garcilaso de la Vega. https://bit.ly/3u8fzIo.

Llerena, L., y N. Sánchez. 2020. “Análisis a la identificación de redes de contagio y aislamiento social como estrategia de prevención en salud pública frente a la pandemia COVID-19 (coronavirus)". Figshare. https://doi.org/10.6084/m9.figshare.12110655.v1

Márquez, C., B. Moreno, y D. Ruiz. 2019. "Firma y presencia del gatekeeper en el periodismo ecuatoriano. Estudio de caso: El Comercio". Revista Ibérica de Sistemas e Tecnologias de Informação (E20): 670-82. https://bit.ly/3cjGifn.

—, N. Ulloa, y Y. Ramos. 2018. "Interaction Gap: From the Bit to the Resurgence of a New Information and Communication System”. En International Conference on Information Technology \& Systems (ICITS 2018), editado por A. Rocha y T. Guarda, 1065-75. Springer. https://doi.org/10.1007/978-3-319-73450-7_101. 
Montoya, R. 2020. “Quédese en casa, mano dura y democracia”. La Mula. 14 de mayo. https://bit.ly/2Lzad8B.

Navarrete, J. M. 2020. “Modernidad, Covid-19 y colonialidad en el Perú”. Notas Introductorias. Investigaciones Sociales 23 (43): 107-18. https://bit.ly/3iXB36u.

PE. 2020. Decreto Supremo N. ${ }^{\circ}$ 044-2020-PCM (Normativa sobre Estado de Emergencia por Coronavirus). https://bit.ly/3t9kQ2H.

PE Defensoría del Pueblo. 2020a. "Reporte regional de Lambayeque y La Libertad al día 09.04.2020”. Defensoría Peruana del Pueblo. https://bit.ly/2XL9a83.

-. 2020b. "Minsa debe asumir conducción de acciones de control del COVID-19 en Arequipa y Callao". Defensoría Peruana del Pueblo. https://bit.ly/2LYgiek.

PE INEI. 2020. "Informe técnico. Situación del mercado laboral en Lima Metropolitana.

Trimestre móvil”. Instituto Nacional de Estadística e Informática. https://bit.ly/3oVns1R

Perlman, S. 2020. “Another Decade, Another Coronavirus”. New England Journal of Medicine 382: 760-2. https://doi.org/10.1056/nejme2001126

Ramos, Y., C. Márquez, I. Argüello, E. Guzmán, A. García, y C. Acosta. 2020. “Aproximación al periodismo cuántico: La próxima revolución”. Revista Ibérica de Sistemas e Tecnologias de Informação (E32): 532-45. https://bit.ly/2MDfETR.

Ramos Obregón, V. 2019. "La representación de las personas con discapacidad en cuatro periódicos de Lima: El Comercio, La República, El Peruano y Trome”. Tesis para optar el título profesional de licenciada en Periodismo, Pontificia Universidad Católica del Perú. https://bit.ly/3t0FPEZ.

Ruiz, G., y A. León. 2020. "Evolución de la enfermedad por coronavirus (COVID-19) en Ecuador". La Ciencia al Servicio de la Salud 11 (1): 5-15. https://bit.ly/3nS6j7C.

Salaverría, R. 1999. "De la pirámide invertida al hipertexto: Hacia nuevos estándares de redacción para a prensa digital". Novatica 142: 12-5. https://bit.ly/36DHjvp.

Shanon, E. 1948. "A Mathematical Theory of Communication”. The Bell System Technical Journal 27 (3): 379-423. https://bit.ly/36om4NP.

Toffler, Alvin. 1992. La tercera ola. Barcelona: Plaza \& Janés.

Vedral, V. 2018. Decoding Reality: The Universe as Quantum Information. Oxford University Press.

Wallace, A. 2020. "El coronavirus en América Latina: Así avanza la pandemia de covid-19 en la región". BBC News. 3 de abril. https://bbc.in/3yAgTXE.

World-O-Meter. 2021. “COVID-19 Coronavirus Pandemic”. World-O-Meter. Accedido 24 de mayo. https://bit.ly/2MhgOoe. 3 de enero de 2021.

Zhu N., Zhang D., Wang W., Li X., Yang B., Song J., Tan W. et al. 2020. “A Novel Coronavirus from Patients with Pneumonia in China, 2019”. New England Journal of Medicine 382: 727-33.

https://doi.org/10.1056/NEJMoa2001017. 